\title{
Sonnet as Closed Form and Open Process
}

\author{
REBEKKA LOTMAN
}

\begin{abstract}
The article attempts to highlight two aspects of the sonnet's semiotic mechanisms from which the dynamics and openness of this form emerge. Firstly, in the production of meaning from the synchronic aspect and secondly, diachronically viewing the sonnet as a process that has a tendency towards the constant opening of this canonical form. So the boundaries of the sonnet are not only closing the form but also lead every single sonnet towards opening.

The paper aims to indicate through the history of the sonnet and some exemplary cases the essential characteristics of this canonical form of poetry, suggesting that inner openness and flexibility is in the very core of the sonnet.

It is suggested that experimenting with the form is very essential to the sonnet; stretching the limits of the sonnet helps to mark its boundaries and at the same time these dynamics stand for its longevity. This is the reason why the sonnet has remained a challenge over centuries in so many cultures.
\end{abstract}

Keywords: sonnet, poetry genres, semiotics of poetry, comparative poetics

DOI: http://dx.doi.org/10.12697/IL.2013.18.2.03

The most general definition of a sonnet is that the sonnet is a closed or fixed form, as opposed to open poetry, which refers to free verse. This term includes presuppositions that can create misleading assumptions about the very nature of the sonnet. Purely terminologically, the concept of free verse (vers libre) is associated with freedom, in turn indicating dynamism, openness and variability, while the sonnet - like all the other canonical poetry forms - connotes fixedness, a closed nature, completeness. Even though it has been suggested that "despite its name, closed form poetry does not have to be confining or conservative", the tendency to experiment with this prescribed form is considered as a quite recent phenomenon, something very modern or contemporary: "And, because contemporary poets do not necessarily feel bound by rules or restrictions about what constitutes "acceptable" poetic form, they experiment freely, trying to discover the form that best suits the poem's purpose, subject, language, and theme." (Kirszner, Mandell 2006: 571) 
LOTMAN

Though there is a lack of critical reflection on the terms closed form and open form in the theoretical papers, two sonneteers, Paul Muldoon and Jeff Hilson have pointed out in an interview, which was included in a recent compendium of sonnet studies, the problematic of these terms (Muldoon, Tyler, Hilson 2012). Paul Muldoon claims that "[...] the description of the sonnet as a 'closed' form is itself a bit closed. It fails to take into account that the sonnet is no more closed than an arena is closed [...]"; and his colleague Jeff Hilson suggests that:

So-called 'open-form' poetry also requires closed operations within it for it to work and to be perceived as open. A truly 'open' poetry could not exist. [...] That aside, there are various ways to avoid restrictions of what is perceived to be 'closed' in a form such as the sonnet. One method is to disrupt those aspects of the poem that are perceived as closing it off, its signifiers if you like, such as structure, shape, rhyme scheme, metre, as well as content. (Muldoon, Tyler, Hilson 2012: 11)

One very important article in revealing the sonnet's open nature is Clive Scott's paper from 1976, "The Limits of the Sonnet" (see Scott 1976). Scott claims that the sonnet - more than any other poetic form - is capable of reinventing itself. According to Scott, the sonnet can absorb new poetic and cognitive elements without changing its fundamental character.

In this article I would like to highlight two aspects of the sonnet's semiotic mechanisms from which the dynamics and openness of this form emerge. Firstly, in the production of meaning from the synchronic aspect - each particular sonnet's significance cannot be seen apart from its intertextual relations and thus its significance is essentially open and this openness is much more inescapable than in the case of the production of meaning in free verse; and secondly, diachronically viewing the sonnet as a process that has a tendency towards the constant opening of this canonical form. So the boundaries of the sonnet are not only closing the form but also lead every single sonnet towards opening. This paper's aim is not to give an exhaustive overview of the sonnet's more than 780-year-old history, but to indicate through some exemplary cases from the sonnet's rich history the essential characteristics of this canonical form of poetry, suggesting that inner openness and flexibility is in the very core of the sonnet. 
Sonnet as Closed Form and Open Process

\section{Sonnet by definition}

Even the briefest dictionary of literary terms or poetical handbook provides us with the definition of this canonical verse form. For example in Oxford's Concise Dictionary of Literary Terms (Oxford University Press 2001: 239-240) is written re sonnet:

A lyric poem comprising fourteen rhyming lines of equal length: iambic pentameters in English, alexandrines in French, hendecasyllables in Italian. The rhyme schemes of the sonnet follow two basic patterns.

1. The Italian sonnet (also called the Petrarchan sonnet after the most influential of the Italian sonneteers) comprises an 8-line 'octave' of two quatrains, rhymed abbaabba, followed by a 6-line 'sestet' usually rhymed $c d e c d e$ or $c d c d c d$. The transition from octave to sestet usually coincides with a 'turn' (Italian, volta) in the argument or mood of the poem. In a variant form used by the English poet John Milton, however, the 'turn' is delayed to a later position around the tenth line. Some later poets - notably William Wordsworth - have employed this feature of the 'Miltonic sonnet' while relaxing the rhyme scheme of the octave to abbaacca. The Italian pattern has remained the most widely used in English and other languages.

2. The English sonnet (also called the Shakespearean sonnet after its foremost practitioner) comprises three quatrains and a final couplet, rhyming $a b a b c d c$ defefgg. An important variant of this is the Spenserian sonnet (introduced by the Elizabethan poet Edmund Spenser), which links the three quatrains by rhyme, in the sequence ababbabccdedee. In either form, the 'turn' comes with the final couplet, which may sometimes achieve the neatness of an epigram.

This is the most general and indisputable definition - the sonnet is a prescribed verse form with certain rules, it has fourteen lines and in different languages it is written in a different metre; also there are two main subgenres, the English and Italian sonnets, and both of them have a few subvariants as well. The differences between various treatments appear mainly in the question of the sonnet's boundaries - what counts as a sonnet, when must we talk about modifications to the sonnet form and when we cannot count the poem as a sonnet at all. According to Michael R. G. Spiller, for instance, there is the basic or simple sonnet of which all others are variations. It has proportion, is divided into eight and six lines and an extension, has ten- or eleven-syllable lines and has fourteen of those. 
And any poem which infringes one of these parameters will remind us of a sonnet quite closely; a poem which infringes two will be more difficult to accommodate, but we will probably try to establish some procedure to account for the deformation; and a poem which infringes all three will not be recognisable as a sonnet at all, and we will regard it as something else unless there is contextual pressure - if, for example, we found it in the middle of a group of normal sonnets. (Spiller 1992: 3-4)

So a poem's sonnetness cannot be found only within the framework of a poem but the context is also significant. From the phenomenological point of view, a sonnet is not an exact combination of some formal features, but a sonnet is a sonnet as far as the reader perceives it to be a sonnet. Strict usage of the term - and the word strict is a common epithet characterizing the sonnet form itself - allows calling a poem sonnet only if all the above mentioned conditions are met: the right number of syllables and verses, the right metre and the right rhyme schemes. From this standpoint, the sonnet is a ready-made form that the poet can fill with his/her words; so the poet's creativity lies in the ability to fill this space with his/her own words, although even here there are restrictions - in the classical sonnet word repetitions are not allowed, also there are thematical restrictions and the turn (volta) must be located either at line 8 (in the Italian and French sonnet) or at line 12 (in the Shakespearean or Spenserian sonnet). Because of its many requirements, the writing of a sonnet has been seen as the ultimate achievement. "Writing a good Petrarchan sonnet is difficult, writing a superb one is all but impossible," remarks the literary critic Paul Fussell (Fussell 1965: 124). The sonnet form is also often seen as something that takes freedom from poetry. For example, Jacob Burckhardt has called the sonnet the Procrustean bed (Burckhardt 1958: 187); also, the famous couplet from one of the most prominent Estonian poets, Juhan Liiv (1864-1913) says: Kes laulab kõlavais sonettides, / raudriideis lõbutseb see lilledes. [The one who sings in sonorous sonnets / is revelling in the flowers wearing armour.]

Considering the sonnet as a static abstract structure, as an ideal sonnet (in Plato's sense), we can really see this form as armour or, even worse, the Procrustean bed with which an author can put himself to the test. According to Nicolas Boileau, the French poet and leading neo-Classical literary critic, composing a sonnet is the punishment that Apollo sent to poets to drive them to despair (Boileau 1815: 12). The fact that a sonnet can be defined as a certain structure that resembles a mathematical formula, while free verse is much harder to define - and this is usually done by negation (what the free verse is not) - refers also to the sonnet's closed and static nature. 


\section{Production of meaning - a particular sonnet}

The first aspect of the sonnet's inner openness lies in every individual sonnet's production of meaning. Michael Riffaterre distinguishes between the poem's meaning and significance - the term meaning refers to the information conveyed by the text at the mimetic level, while significance stands for the poem's formal and semantic unity; and this unity is the characteristic feature of the poem. In other words, from the standpoint of meaning the text is a string of successive informational units; from the standpoint of significance the text is one semantic unit (Riffaterre 1984:2-3). Although the sonnet is a closed, fixed form, the premise of the sonnet's existence is other sonnets and its significance in Riffaterre's sense - as is the case with all other canonical verse forms' significance - can fully open up only in relation to other poems written in the same form. According to Mihhail Lotman, the meaning of the verse form consists of three components: 1) the synaesthetic influence of the material or construction, 2) the rhythmical-syntactical potential of the verse metre; 3) the traditional associations of the given verse metre (Lotman 2012: 37). In the sonnet's case, the first point regarding a poem's synaesthetic influence brings to focus one of the most characteristic features of the sonnet: its bipartite structure and the asymmetry of these two parts. It is often suggested that the sonnet's structure itself has an effect on its meaning. As John Fuller says, this unequal relationship is of far greater significance than the fact that there are fourteen lines in a sonnet. "This bipartite structure is one of observation and conclusion, or statement and counter-statement." (Fuller 1972:2) But the third point, the traditional associations, is also very important in case of prescribed verse forms - and not only the traditional associations of the given metre, but the given form with all its components - the rhyme schemes (or even rhyme types), the position of the turn, the chosen strophics etc. - and of the sonnet form as a whole as well. Every sonnet is very explicitly intertextually linked with previous sonnets - the whole significance of a sonnet can be seen only in the context of other sonnets. And due to the great popularity of the sonnet over time, the relevant intertextual chain is here almost infinite. The significance of the sonnet lies not only in the previous sonnets written in the same cultural space, but the intertextuality goes beyond the boundaries of language. The form's conventional or traditional meaning connotations cannot be seen apart from the whole history of the sonnet, the world's sonnet culture; they can be traced down to the first sonnets, written in Sicily.

The sonnet's sense of history is also linked to the sonnet's tendency to reflect the form thematically - sonnets on sonnets form one important theme of sonnets. One of the most famous sonnets of this kind, "A Sonnet", belongs to 
Dante Gabriel Rossetti (1828-1882), starting with the line: A Sonnet is a moment's monument. ${ }^{1}$

And furthermore, the intertextuality in the case of the sonnet appears on many more levels than in the case of free verse - not only because of the huge amount of sonnets written during its almost 800 years of history, but also because of its numerous requirements. As the classical sonnet includes almost the maximum amount of technical requirements - metre, rhyme, lines, strophics, thematical and lexical level - and all of these can be semiotically viewed as different languages in a poem's significance, there are more possibilities to refer to other sonnets. So all these different semiotic languages in a poem provide sonnets with extra possibilities for intertextuality - for example you can cite one sonnet's rhyme chain; at the same time different metres, rhyme schemes etc. can contain a symbolic (in the Peirceian sense) or conventional meaning. So the significance of closed or fixed forms is characterized by extreme openness - you cannot understand any canonical poem as a canonical poem only inside its fixed form, you can read a closed form as a closed form only in the context of other poems of its kind. In other words, the fixedness of all closed forms is dependent on an innumerable amount of other poems of the kind; the closed form can exist and have meaning as a closed form in an open chain of poems. Hence a sonnet as a canonical verse form belongs to a chain of meaning different from open poetry; openness towards other sonnets is essential here.

\section{Production of meaning - sonnet as a process}

The sonnet's dynamic nature lies not only in every particular sonnet's mechanisms of meaning; the picture becomes more diversified and ambivalent, if we trace its long history through different cultures of poetry. Paradoxically, thanks to its extreme amount of rules and regulations, thanks to its maximum limitedness, the sonnet is a form that is accompanied by constant opening. The sonnet is a dynamic phenomenon associated with endless alteration. Often the reason for the sonnet's longevity, the reason that the sonnet is so popular even more than 780 years after its invention - is seen in its ingenious structure, more precisely in its asymmetry (in the above mentioned bipartite structure). I would like to point out that the other reason that this form is still important in the $21^{\text {st }}$ century's Western poetry is, by all accounts, associated with its essential not-getting-ready, its infinite potential for alteration.

1 On sonnet's self-reflective, so-called autometapoetical function see Lotman, Lotman \& Lotman 2009. 
In the history of the sonnet we can see a bidirectional development - it is a constant affirmation and reinforcing of its tradition and the same time it is a history of alteration, a dynamic process which depends on its time and space, i.e. not only language but also its social and cultural context. The sonnet's history and its geography form an integral whole. The transplantation of the sonnet form into different poetry traditions can be compared to the colonizing process. In some sense it is the Europization of a verse tradition. If hexameter and antique metres constitute the primary school of this Europization then in high school the mandatory course is the sonnet.

The sonnet was invented in Sicily in the court of Frederick II who reigned from 1208 to 1250 over the Southern part of Italy; a small group of poets worked for him and from this period there remain in existence thirty five sonnets, most of them - twenty five - being ascribed to the emperor's notary from Apulia, Giacomo (Jacopo) da Lentini. Beside the fact that his poetic inheritance launches one of the longest lived and vivid canonical poems, there is not much known about his life. ${ }^{2}$ Da Lentini was probably born in 1210 and died in 1240. Twenty-five sonnets (of thirty-five which survive from this period) are attributed to him. ${ }^{3}$ It is not possible to suggest which one of these sonnets was the first one - all the sonnets have 14 lines, all of them are written in endecasillabo - which was the standard metre at this time in Italian verse - and divided into the octave and sestet. The rhyme schemes of the octaves are ABABABAB; the sestets vary CDE CDE (15), CDCDCD (9), and there is one sonnet where the rhyme chain of octave continues in the sestet: AABAAB:

All the sonnets except one deal with the theme of Love, and all are spoken by and /I/ who occasionally identifies himself as coming from town of Lentino (now Lentini). [...] but it is also startling, in that da Lentino appears to have invented the sonnet perfectly immediately: only one of his sonnets, 'Lo viso, e son diviso da lo viso' (I see the face, and yet I'm parted from it'), seems in any way primitive, in having the sestet repeat the rhymes of the octave, $A B A B$ $\mathrm{ABAB} A \mathrm{AB} \mathrm{AAB}$ - a trick which blurs the fundamental difference between octave and sestet. (Spiller 1992: 13-14)

2 For one the most elaborated essays on Giacomo da Lentini's life and on the context where the first sonnets were born see Paul Oppenheimer, "Frederick II, Giacomo da Lentino, and the Earliest Sonnets" (Oppenheimer 1989: 13-25).

3 The exact number varies, in some sources it is 22 sonnets. 
LOTMAN

It has been suggested that the very invention of the sonnet was one of the most remarkable events in the history of Western poetry - not only because a poetic form was born that became the most popular and long lived form in Western poetry, but the form itself marked the birth of the modern mind:

\begin{abstract}
Modern thought and literature begin with the invention of the sonnet. Created in the early duecento by Giacomo da Lentino, a notaro, or important court official and probably lawyer at the emperor Frederick II, it is the first lyric form since the fall of the Roman Empire intended not for music or performance but for silent reading. As such, it is the first lyric of self-consciousness, or the self in conflict. (Oppenheimer 1989: 3)
\end{abstract}

It has also been claimed that the invention of the sonnet marks an inward turn in (Italian) poetry, a lyric becomes a reflection upon reflection: "The sonnet form thrives on debate within the self, a thorny internal monologue. But it also reins in, and rounds off, thinking, and so makes inwardness complete." (Burt, Mikics 2010: 7) From its birth the sonnet started quickly to spread in Italy, from mid-thirteenth century survive around 125 sonnets; and next to the Sicilian School there emerged the Tuscan School, led by Guittone d'Arezzo, and the Roman School of sonneteers - the most famous authors to adopt the sonnet form here were Cavalcanti, Dante, and in the $14^{\text {th }}$ century, Francesco Petrarch. The latter gave his name to the one of two most influential developments of this verse form, the Petrarchan sonnet, which is often mistakenly thought to be the original form of the sonnet. Nevertheless, the Petrarchan sonnets were neither the first ones nor did he invent this certain type of sonnet. Instead of da Lentini's open quatrain ABABABAB, Petrarch's rhyme scheme for the octave (or two quatrains) is an envelope rhyme ABBAABBA, but this sonnet form was primarily used by d'Arezzo. However, without any doubt it was Petrarch who made this form famous: d'Arezzo wrote only two out of his 251 sonnets with the closed octave while in Petrarch's Il Canzioniere, which includes, alongside 317 other poems, sonnets, this rhyme scheme is pervasive. It is also interesting to note that the sonnet was not only absorbed by Hebrew poetry in the same century da Lentini invented it, at the end of the thirteenth century, by Immanuel of Rome (1261-1328), but also that the great majority of his sonnets are rhymed ABBAABBA/CDECDE. ${ }^{4}$ Dvora Bregman has pointed out: "In establishing the classic sonnet, Immanuel thus preceded Petrarch by more than fifty

4 For the Hebrew sonnet during the Renaissance and the Baroque see Dvora Bregman's meticulous monograph The Golden Way (Bregman 2005). 
years." (Bregman 2005: 25) Immanuel of Rome wrote sonnets both in Italian and Hebrew, synthesizing the Roman rhyme scheme with the Arabic verse system (Arud). So Hebrew was the first language to which the sonnet form was transplanted from Italian.

Yet the sonnet belongs above all to Western culture. ${ }^{5}$ Sonnets reached the Pyrenees even before the French, in the $14^{\text {th }}$ century. The first sonnet written outside Italy is credited to Marqués de Santillana, who wrote between 1438 and 1458 , more than sixty years after Petrarch's death in 1374, forty-two sonnets in Spanish. Nevertheless, these sonnets remained exceptional and the form did not spread outside Italy until 1520 , but during the $16^{\text {th }}$ century the sonnet started to spread explosively to different cultures. In Spain, quite a unique development, concerning surpassing the limits of the genre, can be noticed. On the one hand, sonnets continued both in Spanish and Portuguese poetry the important short poetry tradition of these countries, on the other hand, the sonnet found its way to drama. In Spanish baroque drama - for example in Lope de Vega's works, the character sometimes steps onto the stage and presents a monologue in the sonnet form. Even more, sometimes one character presents one part of the sonnet, the other one continues, presenting the next part and so on - hence the whole sonnet appears in the form of dialogue.

Around the 1520s, the sonnet moved quite concurrently to France and England (where a very influential Petrarchan tradition arose as well) and further - once again - to the Pyrenees. These four hearths - Italy, France, England and Spain (however, the latter is more marginal) signify the coordinate axis of the European sonnet. The German sonnet, which was the most important source for the Estonian sonnet, was born very much later, in the first half of the $17^{\text {th }}$ century.

At the center of a researchers' interest is usually the opposition between the Italian and French sonnet: Italian sonnets have eleven syllables in each line, i.e. asymmetrical metre, and feminine endings (except sdrucciola with dactylic ending, but both sdrucciola and rare masculine endings - rima tronca - are exceptional and the rules did not involve these). In French sonnets, two phases and two different types can be distinguished. The first is associated with

5 Sonnets in the Eastern world are quite a recent phenomenon and belong to the beginning of the $20^{\text {th }}$ century. For example, the first sonnet in the Turkish language was “Bir Şi'r-i Na-Nüvişte" (An Unwritten Poem), written by Cenap Şahabettin (18701934). Kyukin Susukida introduced the sonnet form into Japanese poetry (1877-1945). Etc. It is also interesting to mention that the Arabian sonnet is usually written in Arud and the rhyme scheme is AAAA/BBBB/CCC/DDD, Japanese sonnets are without rhyme and each line consists of 5-7 syllables. 
French Renaissance poets of $16^{\text {th }}$ century, a group called La Pléiade (above all Pierre Ronsard and Joachim du Bellay) - the metre became even-numbered, asymmetrical ten syllable verse $4+6$ and, what is more important, the rule of alternation of feminine and masculine endings was imposed).

The French sonnet maintained its classic form during the $17^{\text {th }}$ century Classicism with Nicolas Boileau's and his successors' works. Boileau formulated strict rules for the sonnet, including not only the metre and rhymes but syntax (avoiding enjambement) and lexicon as well - no lexical words were allowed to repeat. Here the sonnet brought together a strictly symmetrical form (twelve syllables, 6+6) with asymmetrical architectonics $(4+4+3+3)$; quatrains and tercets tended in turn to form bigger units, so the main division was $8+6$ verses.

In England the fate of the sonnet was quite different; the Renaissance began in England centuries later compared to Italy, and the first sonnets in English were introduced by Sir Thomas Wyatt at the beginning of the $16^{\text {th }}$ century, after which a cult of Petrarchan poetry emerged. This created a good ground for the sonnet's popularity. However, in England the sonnet's formal boundaries were not as strict as in Romance countries and sometimes it happened that the poet did not exactly know the meaning of the word 'sonnet' and used it as a synonym for the lyrics ${ }^{6}$ (for example John Donne's Songs and Sonets, where none of the poems are written in the traditional sonnet form). So in some cases the poem designated as a sonnet bore none of a sonnet's formal characteristics. Also there were no influential and normative poetics with strict rules of versification comparable to Opitz's in German and Boileau's in French poetry culture. As mentioned above, besides the classic Petrarchan sonnet form, there arose two essentially new variants of the form, connected to the Italian sonnet, above all, by fourteen lines - the Shakespearean and Spenserian sonnets. If the sonnet's most important characteristic is its asymmetrical structure, then in the Shakespearean sonnet the proportions are absolutely different: it consists of three quatrains and one couplet $(4+4+4+2)$. In the Italian structure of $4+4+3+3$ the proportion is $8: 6$ and this form itself tends to lead towards contemplation - for instance, posing a question in quatrains (8) and answering in tercets $(6)$ - but the Shakespearean sonnet form with a single ending couplet against three quatrains (12:2) gives an epigrammatic value to the last lines. The other important thing about the Shakespearean sonnet is the number of rhyme partners - the quatrains of the original Italian sonnet are based on two rhyme chains (ABBA/ABBA or ABAB/ABAB), in the Shakespearean sonnet every quatrain usually consists of two rhymes (ABAB/CDCD/EFEF).

6 The same tendency was in French literature, the trobadours used the word Sonnet to designate short poems and songs like chansons (Richaud 1867: 4-5). 
It has been claimed that this transformation of the form is associated with the fact that in the English language there tend to be fewer rhyming words for full rhymes - the rhyme scheme $\mathrm{ABAB} / \mathrm{CDCD} / \mathrm{EFEF} / \mathrm{GG}$ gives a poet a better chance to express himself freely without getting tangled in the form.

To German literature the sonnet came under the influence of French, Italian and Dutch poets and the first authors here were Martin Opitz and Georg Rodolf Weckherlin. In the German sonnet form the strong influence of the Pléiade appears in two aspects, first in the emphasis on the alternation of masculine and feminine rhymes, and, secondly in the preference for the 'French type' of sestet, with a couplet effect in verse lines 9 and 10 (Yates 1981: 14).

According to the French bibliographer Hugues Vaganey, between 1530 and 1650 in Italy, France, England and Germany some 3000 writers produced about 200000 sonnets (Spiller 1992: 83). Besides geographical expansion and crossing the boundaries of languages very soon after the sonnet's birth, the sonnet started to stretch its formal boundaries and the variations of form started to take place. As the sonnet consists of the maximum number of rules (concerning rhymes, strophics, metre, sometimes even themes), there are a maximum number of possibilities to alter. Throughout the centuries in different countries different variations of sonnets were born. As we saw already, the first transformations of the form are language-dependent, also the general context of poetical conventions in a given tradition play an important role (règle de l'alternance in Classical French poetry, Martin Opitz's poetics influence on German sonnets etc.). The sonnet has not got any ready-made single "true" structure; it is rather formed by the sum of its multiple contexts and is constantly transforming.

But also many other experiments with the sonnet form started to appear; and it is interesting to see that these variants arose in different poetic cultures. Thus this tendency is rather universal, the very part of the form itself.

Firstly, rhymes, which provide very fertile possibilities for variations. From the outset, there were different rhyme schemes. As mentioned already, da Lentini wrote a sonnet on two rhymes: ABABABAB/AABAAB. And from the invention of a sonnet, the transformations of rhyme schemes started to take place, there are numerous possibilities to combine the rhymes of the sonnet's fourteen lines and these variants have been realized independently in different languages and poetic cultures. Even the most conventional Petrarchan sonnet has got several types: envelope quatrains (ABBA/ABBA) are followed by tercets rhymed $\mathrm{CDC} / \mathrm{DCD}, \mathrm{CDD} / \mathrm{CEE}, \mathrm{CDE} / \mathrm{CDE}, \mathrm{CDE} / \mathrm{EDC}$. In quatrains the rhyme scheme ABBA/ACCA is used both in Byron's sonnets (tercets DED/ EDE), also in Wordsworth's sonnets, which continue with the third quatrain DEDE and the ending couplet (FF). 
LOTMAN

Moreover, in one instance in France during the $17^{\text {th }}$ century it became popular to write sonnets with given rhymes - bouts rimés; the invention of these rhymes is attributed to Dulot, a French poet of the $17^{\text {th }}$ century. Also, blank sonnets or sonnets without rhymes and so forth emerged in different poetic cultures. One could go on. The list of different rhyme schemes used in the history of the sonnet cannot be given here - it is too voluminous for this article. Although in poetic handbooks there is no all-inclusive overview of these plentiful variants, there are some web pages mapping all possible sonnet types. ${ }^{7}$

Different rhyme schemes can lead to the transformation of the sonnet's strophic structure: the inverted sonnet (the Italian $3+3+4+4$ or $4+3+3+4$, the English $2+4+4+4$ or $4+2+4+4$ etc.), the double half sonnet $(4+3+4+3)$ etc. Also, many expanded and condensed sonnets appeared, primarily caudate or tailed sonnets (sonetto alla coda) with one extra tercet were very popular in the $14^{\text {th }}$ century, above all in the Tuscan School. Originally, in the Italian tradition, sonnets of this type were parodies or satirical poems, used only for humorous and burlesque purposes (main authors Cino da Pistoia, Antonio Pucci, in the $15^{\text {th }}$ century Domenico Burchiello and Francesco Berni). In contrast, in Hebrew sonnets, sonetto caudate, which emerged at the end of the $16^{\text {th }}$ century, was generally used for festive events (weddings, etc.). Many kinds of tailed sonnets were invented in English poetry, for example Milton's sonnet of twenty lines, George Meredith's sonnet, which brings together the Italian and English sonnet forms $(4+4+3+3+2)$. During the $16^{\text {th }}$ century several types of double sonnets were invented, the first of them was a sonnet with 28 lines $(4+4+4+4+3+3+3+3)$, created by Jean de Boyssière. Also shorter versions of the sonnet emerged, for example the half sonnet $(4+3)$ and the curtailed sonnet $(6+5)$.

As mentioned above, the sonnet must reinvent its metre every time it enters a new language, so in original sonnets the proper metre was endecasillabo, in French the sonnet metre was the alexandrine, in English the iambic pentameter. But in all of these cultures we can find sonnets written in all kinds of metres, even sonnets in free verse that became very popular in the $20^{\text {th }}$ century. Not only different verse systems, but the number of syllables also makes it possible to stretch the boundaries of the sonnet - see for instance Paul de Ressègnier's famous sonnet Épitaphe d'une jeune fille:

The Internet Poetic community Tir na $n O g$ - Land of the Everliving names 135 different sonnet types which have appeared in the sonnet's history. Though this web page does not give an academical overview of the sonnet form (there are also some mistakes, some questionable forms and many forms are missing) this is a great source that reflects the sonnet's variability (tirnanogthelandoftheeverliving.yuku.com). Another similar web page is Every Sonnet, which concentrates on sonnets written in English (everysonnet. blogspot.com). 
Sonnet as Closed Form and Open Process
Fort
Belle
Elle
Dort.
Sort
Frêle!
Quelle
Mort!
Rose
Close
La
Brise
L'a
Prise.

Moreover, here is a Shakespearean sonnet by John Updike, where all verses except the first and third consist not only on one syllable but also on a oneletter-only syllable:

In Love's rubber armor I come to you,

oo

b.

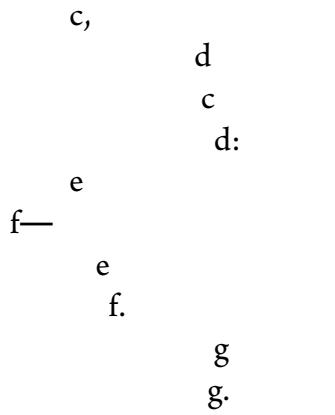

Besides transforming one or many parameters of a single sonnet, there are also numerous different modes to bind sonnets to each other. Michael R. G. Spiller distinguishes between four main types of sonnet sequences: 1) the formal sequence - sonnets linked by repetition of some element of their form: rhyme, syntax, single lines, etc. (Folgore da San Gemignamo, Anne Locke, John 
Donne, and George Macbeth); 2) the narrative sequence - the sonnets are arranged to unfold as a story, people and objects in it are presented as they would be in a novel (Edna St. Vincent Millay $\left.{ }^{8}\right) ; 3$ ) the lyric sequences - every sonnet registers the moods of a reflective persona and these sonnets form a sequence on the basis of being dedicated to the same person, thematic recurrence, etc. (Petrarch's Rime, Elizabeth Barrett Browning, Tony Harrison, John Donne, and William Shakespeare); 4) a philosophical sequence - a sequence which exhibits a philosophical thought (Christina Rossetti, “The Threads of Life”, and Reiner Maria Rilke, Sonnets to Orpheus) (Spiller 1997: 140-141).

Different kinds of sonnet crowns or coronas arose already among Renaissance sonneteers, where the units are not linked only thematically, but in lines and rhyme as well:

In a corona proper, the sonnets are linked through repetitions of whole lines. In the simplest form, the last line of one sonnet becomes a first line of the next, until in the final sonnet we return in the last line to the first line of the whole sequence. (Fuller 1972: 41)

The most common crowns consisted of seven or nine sonnets, but the most elaborated form of corona, heroic crown, was invented in the $15^{\text {th }}$ century by the Siena Academy, comprising fifteen sonnets, in which fourteen sonnets are made up as described above and ending with sonetto magistrale in which all the link-lines of the previous fourteen sonnets appear in order.

Hence we can see a constant double-oriented development in the history of the sonnet - first, the reinforcement of the most traditional and classical forms (but even here we cannot use the singular forms, as during its more than 700 years of history there are several absolutely traditional and "legitimate" strict verse forms) and secondly, its transformation into new forms. The history of the sonnet is a history of numerous alterations and variations, in this small article only a small part of them are touched upon. As important as formal modifications are those that are lexical and thematic - Baudelaire again reinvents the sonnet and pushes its limits using words and themes that found their way, not only to sonnets, but also to poetry in general. Choosing

8 In Russian poetry there emerged in the second half of the $19^{\text {th }}$ century a narrative poetry in sonnets, this form became especially popular among modernists, for instance Vyacheslav Ivanov's An Argument. A Novel in Sonnets. In this work every sonnet functions as a strophe. In Estonian literature, there is also a novel written in poems and greatly in sonnets, Ivar Grünthal's Peetri kiriku kellad (The Bells of St. Peter's Church, 1962). 
the sonnet to express his decadent feelings and view of life creates an intense tension between the classic form and these very innovative themes in the $19^{\text {th }}$ century poetry. Sandra R. Brennan has pointed out the sonnet's paradoxical position during the modern literary period - at the time of relaxing the more rigid structures to make room for free verse, the sonnet has attracted a number of the most prominent modern poets (Rainer Maria Rilke, George Meredith, Stéphane Mallarmé, W. H. Auden and so on ${ }^{9}$ ). "It is a form as much to be worked against, even overcome, as it is to be recalled and cultivated," marks Bermann (Bermann 1988: 149).

\section{Conclusion}

Thus the sonnet is not only a rigid armour or the Procrustean bed, but if we take a look at its history and production of meaning, we can see rather a living organism the nature of which opens up both in its ideal structure and its divergence from it; the relationship between these two is dialectical. Ever since Giacomo da Lentini invented the sonnet, this poetic form has proved its longevity and vividness. The reason lies not only in the invention of a perfect form for a poem, but also in the sonnet's intrinsic open nature, its ability to transform itself in so many aspects without losing its essence.

In the first instance, at the very moment one language adopts the sonnet and starts to write its "own" sonnets, the most radical transformation takes place - even using another language, modifications occur that are dependent on new material, on the qualities of the language to which the sonnet is being transplanted. The modifications include a poem's rhythm, its metre, its prosody and rhyme lexicon as well. In different languages there are different rhyme chains, rhyming words associate in different languages with different words, so the strict rule of rhymes influences its meaning differently in every language. The cultural context also has a broader influence on poems. The universal model is that after entering one linguistic space, the sonnet tries to imitate the sonnet form that prevails in the culture it came from. For example, the Estonian sonnet was born around 1880 and the main influences came from German poetic culture. Until the beginning of the $20^{\text {th }}$ century, the authors took as a model not the Italian but above all the Austrian and German sonnet (Nikolaus Lenau, Heinrich Heine and others) and during the first twenty years the main aim was to prove that the Estonian language was as suitable to sonnets as all the

9 In Russian poetry the deconstruction of the sonnet started in the middle of the $19^{\text {th }}$ century with the Symbolist poet Innokentiy Annensky (see Lotman 1993). 
other Western languages (Kangro 1938: 53). However, after the form has been absorbed by a poetic culture and authors start to use this form "fluently" (i.e. without unintentional mistakes in its metre, rhymes and strophic structure and the significant level of the poem is facile and corresponds to the contemporary understanding of poetry), authors start to seek possibilities to alter the form, to experiment with it and, because the sonnet has more prescribed restraints than other fixed forms, it has more possibilities for variation.

The sonnet as an ideal structure has a complex of fixed and prescribed rules; the concept of the 'sonnet' is a signifier of this aspect of the essence of the sonnet. Nevertheless, this does not define the sonnet as it opens up in the history of poetry. Seen as a fixed or closed form, the sonnet does not include in its semantic field the dynamic process that the sonnet history really is. Yet, this is the very reason why writing a sonnet means a constant digression from the rules. Paradoxically, the inner openness and dynamism of the sonnet form is dependent on considering this poetic form as fixed and ready-made. The history of the sonnet is a history of constant alteration, transformation and experiment. It is also important that this openness cannot be attributed only to the contemporary sonnet, as many authors tend to do. ${ }^{10}$ Here we can see a double development - no sonnet can be viewed apart from previous sonnets, yet a sonnets' meaning lies not only in a given poem or given poetic culture, but in the sonnet culture as a whole. Secondly, the ideal structure of a sonnet is always floating above every sonnet and has an effect on a sonnet's significance as well.

Sometimes the altering of the sonnet form has been viewed as dissatisfaction with it (for example Bregman 2005: 23), I suggest that this experimenting with the form is very essential to the sonnet: stretching the limits of the sonnet helps to mark its boundaries and at the same time these dynamics ensure its longevity. This is the reason why the sonnet has remained a challenge over centuries in so many poetic cultures.

Indeed, sonnet writing does not mean the creation of something innovative every time; two types of poets can be distinguished, those who ensure the preservation of tradition and those who are searching for new perspectives. Critics tend to oppose sonneteers (and other poets who use classical poetic forms) to

10 See for example Stephen Burt's article on the contemporary sonnet where he distinguishes the formal play as one characteristics of the contemporary sonnet: "the sonnet gets stretched to its limits, broken up and reinvented [...]” (Burt 2012: 246). Of course the tendency to play with the form became more intense with modernist poets but we can see these experiments with the form throughout the whole history of the sonnet. 
those who open new possibilities in poetry, but in the history of poetry we can see that among sonneteers there can be both types of authors as well. When the sonnet enters any poetic culture, it does not mean that besides other abundant ways of writing poetry there is henceforward one additional way to do it - to write it in one ready-made form - but this prescribed form starts to live its own life in the living poetry. This life is much richer than one abstract form can be. These variations must not be regarded as deviations from the sonnet form, but its natural differentiations which form a inseparable part of the sonnet as such. The extreme openness and flexibility is the very reason why this form has maintained its popularity through centuries, sonnet writing is still widespread in the $21^{\text {st }}$ century in European and American poetry.

The paradox is that the sonnet can be just what it is, a dynamic process with different narratives in different cultures mostly because at the theoretical level, in different poetics and anthologies, the form is treated paradoxically as a closed and fixed form.

\section{Rebekka Lotman}

rebekka@tlu.ee

Wismari 39-2

Tallinn 10136

EESTI

\section{Literature}

Bermann, S. L. 1988. The Sonnet Over Time. A Study in the Sonnets of Petrarch, Shakespeare, and Baudelaire. Chapel Hill and London: The University of North Carolina Press.

Bregman, D. 2005. The Golden Way. The Hebrew Sonnet during the Renaissance and the Baroque. Tempe, Arizona: Arizona Center for Medieval and Renaissance Studies. Burckhardt, J. 1958. The Civilization of the Renaissance in Italy. New York: Harper \& Row. Burt, S., Mikics, D. 2010. The Art of the Sonnet. Cambridge, Massachusetts, London, England: The Belknap Press of Harvard University Press.

Burt, S. 2012. The contemporary sonnet. - A. D. Cousins, P. Howarth, eds. The Cambridge Companion to the Sonnet. Cambridge: Cambridge University Press, 245-266.

Muldoon, P., Tyler, M., Hilson, P. 2012. Contemporary poets on sonnet: a trialogue. A. D. Cousins, P. Howarth, eds. Cambridge: The Cambridge Companion to the Sonnet. Cambridge University Press, 6-24.

Edmondson, P., Wells, S. 2004. Shakespeare's Sonnets. Oxford: Oxford University Press.

Every Sonnet $=$ everysonnet.blogspot.com (08.04.13). 


\section{LOTMAN}

Fuller, J. 1972. The Sonnet. London: Meuthen \& Co Ltd.

Fussell, P. 1965. Poetic Meter and Poetic Form. New York: Random House.

Kangro, B. 1938. Eesti soneti ajalugu. Tartu: Akadeemilise Kirjandusühingu toimetised.

Kirszner, L. G., Mandell, S. R. 2006. Portable Literature: Reading, Reacting, Writing. Boston: Wadsworth Thompson.

Lotman, M. 1993 = Аотман, M. 1993. Иннокентий Анненский - разрушитель сонета. - L. Pszczolowska, D. Urbanska, eds., Slowianska metryka porownawcza. $V$ Sonet. Warszawa: Institut Badań Literackich Polskiej Akademii Nauk, 123-131.

Lotman, M. 2012. Verse as a semiotic system. - M. Lotman, M.-K. Lotman, eds., Sign System Studies, vol. 40 (1/2), special issue: Semiotics of Verse. Tartu: University of Tartu Press, 18-51.

Lotman, M.-K., Lotman, M., Lotman, R. 2009. Autometakirjeldus eesti luules II. Acta Semiotica Estica. Tartu: Tartu Ülikooli Kirjastus, 42-67.

Oppenheimer, P. 1989. The Birth of the Modern Mind. Self, Consciousness, and the Invention of the Sonnet. New York, Oxford: Oxford University Press, 13-25.

Richaud, L. 1867. Histoire du sonnet, sa grandeur et sa décadence: entretien littéraire. Cahors: Plantade.

Riffaterre, M. 1984. Semiotics of Poetry. Bloomington: Indiana University Press.

Scott, C. 1976. The Limits of the Sonnet: Towards a Proper Contemporary Approach.Revue de littérature comparée, 50, 237-250.

Spiller, M. R. G. 1992. The Development of the Sonnet. An Introduction. London and New York: Routledge.

Spiller, M. R. G. 1997. The Sonnet Sequence. A Study of Its Strategies. New York: Twayne Publishers.

TirnanOg=TirnanOg-Land oftheEverliving,http://tirnanogthelandoftheeverliving. yuku.com/topic/22634/Sonnet-Variations-Quick-Reference\#.UWF2fKKouSp (08.04.13).

Yates, W. E. 1981. Tradition in the German Sonnet. Bern, Frankfurt am Main, Las Vegas: Peter Lang.

Wagner, J. A. 1996. A Moment's Monument. Revisionary Poetics and the NineteenthCentury English Sonnet. Madison, Teaneck: Fairleigh University Press, London: Associated University Presses. 